\section{The impact of metacognitive strategies and self-regulating processes of solving math word problems *}

\author{
Eda Vula ${ }^{a,{ }^{* *}}$, Rrezarta Avdyli a , Valbona Berisha ${ }^{a}$, Blerim Saqipi ${ }^{a}$, \\ Shpetim Elezi a
}

\author{
Received: 20 August 2017 \\ Revised: 06 Sept. 2017 \\ Accepted: 18 Sept. 2017 \\ ISSN: 1307-9298 \\ Copyright (C) IEJEE \\ www.iejee.com
}

DOI: $10.26822 /$ iejee.2017131886

\begin{abstract}
This empirical study investigates the impact of metacognitive strategies and self-regulating processes in learners' achievement on solving math word problems. It specifically analyzes the impact of the linguistic factor and the number of steps and arithmetical operations that learners need to apply during the process of solving math word problems. Two hundred sixty-three learners, of three classes of third graders $(\mathrm{N}=130)$ and four classes of fifth graders $(\mathrm{N}=133)$ of the elementary cycle from two urban schools of Kosovo, participated in the study. Almost half of the total number of the third and fifth-graders were exposed to metacognitive instruction. The rest of the learners were included in control classes in which they performed tasks without having been given any specific guidance, based exclusively on traditional methods and respective textbooks. All the learners were tested in math word problems twice, before the intervention and after it. Research findings have shown that metacognitive strategies and self-regulating processes that learners use to control their actions, to reason, and to reflect, are one of the main resources that influence their success in solving a math word problem. Although the difference between the pre-test and the post-test results was statistically significant solely with the fifth-grade experimental classes, yet an improved performance was observed in third-grade experimental learners' classes compared to control classes. Theoretical and practical implications of the research are discussed in the end of the study.
\end{abstract}

Keywords: Arithmetic operations, math word problems, metacognition, self-regulation.

\section{Introduction}

In many countries in the world, mathematical education has undergone a number of reforms. Their general characteristic is the focus on mathematical skills that are based on problem solving, which is conceptualized by OECD (2003) as learners' ability to use cognitive processes in solving them (Hickendorff, 2013; Capraro, Capraro \& Rupley, 2012). Problem solving in general, and math word problem solving, in particular, has been given an important place in textbooks and in state evaluations; therefore they are included in almost all mathematics curricula.

According to Kosova Curriculum for pre-university education, application of knowledge in the context of solving problems by appropriate actions is one of the learning outcomes to be accomplished by learners at all levels (The Pre-University Education Curricula Framework, 2016). Problem solving represents one among the eight main competencies of the curricular area of mathematics at all levels; hence, it is included in teaching, in the learning process, as well as in the evaluation of learners' knowledge and skills. On the other hand, the Program for International Student Assessment (PISA) also particularly takes into consideration learners' skills for the treatment of solving problems in real life circumstances (OECD,
2014). Due to this, many researchers and educators have paid particular attention to the process of math word problem solving (Lubin, Houde \& de Neys, 2015; Mevarech et al., 2010; Monroe \& Orme, 2010; Capraro \& Joffrion, 2006; Fuchs, Fuchs, Compton, Powell, Seethaler, Capizzi, Schatschneider, \& Fletcher, 2006; Jonassen, 2003).

Problem solving represents the foundations of all mathematical activities (Fuchs, Seethaler, Powell, Fuchs, Hamlett, \& Jack, 2008; Van de Walle, 2004; Reys, et al., 2001). Frequently these activities have been qualified as very difficult, complex, and distressing for many learners (Jitendra, Griffin, Haria Leh, Adams, \& Kaduvettoor, 2007), and especially when they face math word problem solving. One of the most frequent reasons that make these problems so difficult comprehends their content. Learners are faced with the problem of distinguishing relevant from complementary information due to their difficulties in reading skills, or due to the inclusion of words of a low frequency of occurrence in mathematical vocabulary (Lee \& Leah, 2007). Furthermore, learners frequently translate words, which describe a problem directly into a math expression without making prior attempts to create a mental representation of the problem (Pape \& Smith, 2002). In some cases, learners approach the problem procedurally. As a result of these,

\footnotetext{
"Part of this study with a title "The Effect of Using Metacognitive Strategies for Solving Mathematical Word Problems" was orally presented and published in the Book of Abstracts of the International Conference on Education and New Development 2017 held in Lisbon, Portugal from 24 to 27 June 2017. ${ }^{* *}$ Corresponding author: Eda Vula, University of Prishtina, Faculty of Education, Prishtina, Kosovo. Phone: +377 44134 203, E-mail: eda.vula@uni-pr.edu University of Prishtina "Hasan Prishtina", Kosovo. E-mail addresses: (E. Vula) eda.vula@uni-pr.edu; (R. Avdyli) rezarta.avdyli@uni-pr.edu; (V. Berisha) valbona.berisha@uni-pr.edu; (B. Saqipi) blerim.saqipi@uni-pr.edu; (S. Elezi) shpetim.elezi@uni-pr.edu
} 
as soon as learners encounter numbers, they instantaneously fill in the pages of textbooks translating words directly into algorithms, without comprehending what each number in the math word problem represents (Vula \& Berdynaj, 2011; Jonassen, 2003).

Problem solving, as a rather complex cognitive process, requires from learners to utilize linguistic information, to identify the absence of variables, and to benefit from the models for solving them. This engages learners in identifying the unknown, in constructing mathematical expressions, in explaining and evaluating their mathematical reasoning (Fuchs et al., 2008; Pape \& Smith, 2002). Therefore, it is essential that learners be appropriately instructed to interconnect different meanings of words, the interpretations, the relations with mathematical operations, as well as problems in their daily lives. Nonetheless, many teachers in Kosova continue to apply traditional teaching methods relying exclusively on math textbooks and the requirement to "fill in" the pages with calculations and to perform arithmetical operations (Vula \& Berdynaj, 2011). On the other hand, when learners encounter a task that involves a math word problem, for the majority of learners comprehending and solving it tend to be rather difficult processes. Hence, a more effective approach in teaching in the classroom is required in order to develop learners' abilities of conceptual comprehension of math word problem solving process (Jonassen, 2003).

What creates gaps in the process of solving math word problems is precisely the failure to take into consideration the reciprocal relations in cognitive processes between reading and mathematics. Accordingly, theoretical models and teaching strategies for solving math word problems proposed by many researchers are based on cognitive structures and the use of reading as a tool for enhancing the level of achievement in solving this type of problems (Carparo et al., 2012; Jitendra et al., 2007; Leong \& Jerred, 2001; Mevarech et al., 2010; Österholm, 2005;;Özsoy \& Ataman, 2009;).

Considering the importance of the process of problem solving, teachers as facilitators should assist children in building their mentality regarding math word problems, as well as the relations between various factors (Griffin \& Jitendra, 2009). They should help learners in creating connections between language, problem solving, and mathematical interconnections (Daroczy, Wolska, Meurers \& Nuerk, 2015; Jitendra et al., 2007).

Considering all that has been stated in the previous paragraphs, the principal aim of the present study is to investigate the impact of the linguistic factor in the process of solving math word problems. Furthermore, the study provides the analysis of the influence of the number of steps and operations as variables that need to be utilized by learners in solving math word problems. In addition, the study aims to examine whether age variables are present in education within the low cycle of the formation when learners are still the product of a teacher. Another more specific aim of the study is to assess the importance of teacher's intervention (or absence of it) in the metacognitive process, in the creation of mathematical reasoning, but also in comprehending words and linguistic expressions during the process of solving mathematical problems.

\section{Literature review}

Word problems in mathematics have been vastly included in educational literature mainly due to the fact that the issue is considered to be one of the most difficult in math lessons (De Corte, Verschaffel, \& Op't Eynde, 2000; Hegarty, Mayer, \& Monk, 1995; Lewis, 1989; Stern, 1993). Certain studies have identified a number of sources of difficulties. The majority of them are interrelated with the semantic structure of posing the problem that indirectly influences reading comprehension more than the comprehension of mathematical problems (Daroczy, Wolska, Meurers \& Nuerk, 2015; Haylock \& Thangata, 2007; Hegarty et al., 1995; Pimm, 1991; Verschaffel, Greer, \& De Corte, 2000).

One of the sources of difficulty is reading comprehension and the mean of "the key words" used in math word problems (Boonen, van Wesel, Jolles, \& van der Schoot, 2014; Hegarty et al., 1995; Mevarech, 1999; Pimm, 1991). The majority of learners rely on key mathematical words considering that they always carry "important" information for mathematical operations. Consequently, learners (erroneously) interpret words, such as. "more" or "enlarged for" as a permanent sign of addition, while "less" or "smaller than" as subtraction, or "product of" as multiplication, and "by" as division.

The process of problem solving requires from learners to use linguistic information, identify the missing information, and then define the computing problems. This process engages learners so that they become ready to identify the unknown in the structure of mathematical expressions, explain and justify their mathematical reasoning, and develop their mathematical knowledge through exploring (Fuchs, et al., 2008; Pape \& Smith, 2002).

Learning how to solve math word problems requires first comprehension of information, which is comprised, of the text and then its "translation" or interpretation of the "event" into arithmetical operations expressed in mathematical language (Jonassen, 2003) 0). A strong support in comprehending the unknown words and the terminology is of great importance for learners' success. Mathematical vocabulary is a key factor, which helps learners to improve their skills in solving math word problems (Capraro \& Joffrion, 2006; Krawec, \& Sweeney, 2008; Lee \& Leah, 2007; Monroe \& Orme, 2010; Montague,). Learners will be successful if they learn the meaning of new words, either directly or indirectly, through spoken or written language, as part of their daily experiences. Without conceptual comprehension of the context of problems, they will not be able to "translate" words into mathematical symbols (Capraro \& Joffrion, 2006), or they will continue to fail in preventing mistakes that derive from heuristic intuition on which they base their judgments while solving math word problems (Lubin et al., 2015). Thus, there is a need for students to develop strategies besides understanding the language of the problem and the mathematical language involved in the problem (Özsoy, Kuruyer \& Çakıroğlu, 2015). 
Related to language comprehension, Martinez \& Martinez (2001) emphasize that learner;

"... learn to use language, to focus and work through problems, to communicate ideas coherently and clearly, to organize ideas and structure arguments, to extend their thinking and knowledge to encompass other perspectives and experiences, to understand their own problem solving and thinking processes as well as those of others, and to develop flexibility in representing and interpreting ideas."(p.47).

Conceptual understanding in mathematics is interrelated with reading comprehension if we define reading comprehension as obtaining the meaning of what has been read based on readers' previous knowledge or background information (Willson \& Rupley, 1997). Conceptual mathematical knowledge refers to the comprehension of ideas and generalization that connect mathematical constructions and the relations between them (Hiebert, 1986). On the other hand, procedural mathematics focuses on "step by step" skills and procedures without explicit reference to mathematical ideas.

In order to promote reading comprehension in some studies, the manner of presentation of linguistic information in mathematical problems has been analyzed. Accordingly, if texts or sentences have a consistent language, the term that implies that the order of presenting the information is consistent with the reader's preference (Leong \& Jerred, 2001), then reading comprehension is easier. On the other hand, when the language presented is inconsistent in the sequence of the presentation of the data, or if the data has to be interpreted inversely by the reader, then reading comprehension is more difficult (Bestgen, 2009; Mevarech et al., 2010). Nevertheless, language plays different roles not only due to word order but also due to semantic perspective. In cases when arithmetical problems with one operation, after concepts and relations involved have been understood, should be correctly applied and solved by children (Quintero, 1983). In problems with two or more operations, understanding the relations between concepts is also required; however, there are some additional issues. Quintero (1983) insists that children first need to plan and organize the information, and then understand what arithmetical operations are required to be performed, as well as to identify pairs of numbers for which they should know what kind of mathematical operations need to be applied (Castro-Martinez \& FriasZorilla, 2013). Thus, while one operation problems require only one operation in order to be solved, two operation problems include a question that requires the application of computing operations on a variable; therefore, the more steps are required, the more mental resources are demanded in order to perform the task (Bestgen, 2009).

Since the whole process of comprehending words, the sequence of operations, as well as the final result of a sentence that describes a mathematical problem is extremely overloaded, the best way to understand how learners reason when facing such a problem is to take into account their reflections. In order to do this, an intervention strategy that would measure the process of self-regulation is required. Self-regulation is an "active" structural process which enables achievement of learners' goals, monitoring, and understanding of knowledge; it is an ability to control and guide learners towards the fulfillment of learning goals (Stoeger, Fleishmann \& Obergriesser, 2015). Due to this, learners need to set goals, to select strategies that will help them reach their goal, to apply the selected strategies, and to continuously monitor their own progress.

Self-regulation of learning consists of three main components: cognition, metacognition, and motivation. Cognition includes the abilities necessary for codifying, for memorizing, and for retrieving information. Metacognition includes the abilities, which enable learners to understand and monitor their own cognitive processes. Motivation involves the beliefs and attitudes that influence the usage and the development of cognitive and metacognitive abilities. Each of the three components is essential, but not sufficient for selfregulation (Schraw, Crippen \& Hartly, 2006) and for efficient solving of problems. Although self-regulating processes are the basis for learning in general, selfregulation can be more directly related to early mathematics and the natural requirements of mathematical operations (Blair, Ursache, Vernon-Feagans \& Greenberg, 2015), and consequently with learners' achievements in solving problems in early childhood.

Reading comprehension is essential in solving math word problems. Achievement of comprehension of written texts or sentences is one of the main pillars of the development of reading skills throughout school years. However, the mere fact that children can read does not mean that they also understand what they have read. Therefore, deciphering graphemes into phonemes does not make children skillful readers. A child attains such a skill only through extensive reading, initially reading accompanied by an adult, further on independent loud reading, and finally meaningful silent reading. If the complex nature of language itself, and additionally, the issue of converting linguistic signs (words, sentences, etc.) (Avdyli \& Cuetos, 2012) into mathematical symbols, or arithmetical operations is considered, then it has to be taken into account that frequently the issue of solving math word problems is more than just a "mathematical or arithmetical" issue. It is rather the issue of the very nature of language and of the words used (Capraro et al, 2012).

The present study investigates reading comprehension as a possibility for enhancing solving math word problems. The principal focus of the research is the examination of texts that describe mathematical problems through an analysis, which assesses whether the linguistic information is consistent or inconsistent. Analysis of text complexity that influences the scale of solving mathematical problems is also important for the present study. Consequently, the impact of comprehension of linguistic information in solving mathematical problems, regardless whether application of one or more operations is required is investigated. The research hypotheses of the present study derive from these particular goals. 


\section{Methodology}

This empirical study aims at examining linguistic complexity in formulation of math word problems and analysis of problem solving with regard the number of arithmetical operations. These are actions, which need to be undertaken by a learner in order to reach the solution as well as investigating the efficiency of various metacognitive strategies that are put in function in selfregulating process of learning. Therefore, the study intends to assess the importance of early intervention for developing mathematical thinking and reasoning.

Research based on this type of design aids researchers and educators to better understand how to orchestrate learning experiences among children in a daily educational context, and at the same time, how to develop theoretical ideas regarding the nature of learning (Bell, 2004). Consequently, the research design takes into consideration primarily understanding of the processes and the strategies that help learners to be successful in solving math word problems.

\section{Participants in the research}

The 263 learners of the primary cycle from two primary and lower secondary schools of the municipality of
Prishtina were involved in the research. The participants were the learners of four classes of the third grade $(\mathrm{N}=130)$, the average age being 102 months (SD 2.84 months), and four classes of the fifth grade $(\mathrm{N}=133)$, the average age being 127 months (SD 3.29 months), that is two classes of each grade from both schools. The researchers have not taken into account the tests of 8 learners who have participated neither in the pre-test nor in the post-test.

From the overall number of learners of the fifth grade, 60 learners $(45.1 \%)$ were included in two experimental classes in which intervention strategies (instructions for solving math word problems) were given, whereas 73 learners (54.9\%) were engaged in control classes, in which they performed their tasks without any specific instruction, based solely on traditional methods and respective textbooks. On the other hand, from the total number of third-grade learners, 66 of them $(50 \%)$ were included in experimental classes whereas 64 (49.2\%) were part of the control classes (table 1). Table 2 presents the data regarding the number of learners based on their general success scores. All learners were identified as learners with sufficient, good, or very good success score.

Table 1. Sample distribution according to classes and gender

\begin{tabular}{|c|c|c|c|c|c|c|c|c|c|}
\hline & \multicolumn{5}{|c|}{ Experimental group } & \multicolumn{4}{|c|}{ Control group } \\
\hline & \multicolumn{5}{|c|}{ Age } & \multicolumn{4}{|c|}{ Age } \\
\hline & & $\mathrm{N}$ & $\%$ & Mean(month) & Std.Dev & $\mathrm{N}$ & $\%$ & Mean (month) & Std.Dev. \\
\hline \multicolumn{10}{|c|}{ Third grade } \\
\hline & Female & 40 & $60.60 \%$ & \multirow{2}{*}{102} & \multirow{2}{*}{2,84} & 38 & $59.40 \%$ & \multirow{2}{*}{127} & \multirow{2}{*}{3.28} \\
\hline & Male & 26 & $39.40 \%$ & & & 26 & $40.60 \%$ & & \\
\hline \multicolumn{10}{|c|}{ Fifth grade } \\
\hline & Female & 26 & $43.30 \%$ & & & 40 & $54.80 \%$ & & \\
\hline & Male & 34 & $56.70 \%$ & & & 33 & $45.20 \%$ & & \\
\hline Total & & 126 & & & & 137 & & & \\
\hline
\end{tabular}

The four full-time teachers of the respective classes (two of the third and two of the fifth grade), were also active participants in the research. They were given specific instructions regarding the "modus-operandi", as well as the manner of intervention to be applied in the realization of tasks (solving math word problems) for the first time, and their realization for the second time.
Considering the fact that throughout Kosova the same curriculum is implemented and the same textbooks approved by the Ministry of Science and Technology (MEST) are used, and at the same time, instruction is delivered in heterogeneous classes and instructors are required to have the same qualification, the selected sample is considered representative of learner population of Kosovo.

Table 2. The distribution of sample according to overall success score

\begin{tabular}{|c|c|c|c|c|c|c|}
\hline \multirow[b]{2}{*}{ Overall success } & \multicolumn{2}{|c|}{ Experimental group } & \multicolumn{4}{|c|}{ Control group } \\
\hline & Sufficient & Good & Very good & Sufficient & Good & Very good \\
\hline Third grade & $8(12.1 \%)$ & $19(28.8 \%)$ & $39(59.1 \%)$ & 4 (6.2\%) & $13(20.3 \%)$ & 47 (73.4\%) \\
\hline Fifth grade & $5(8.3 \%)$ & $20(33.3 \%)$ & 35 (58.3\%) & $8(11.0 \%)$ & $21(28.8 \%)$ & $44(60.3 \%)$ \\
\hline
\end{tabular}

\section{Research instruments}

In order to measure the impact of the linguistic factor and its complexity in solving math word problems, a number of word problems were designed incorporating a combination of linguistic complexity, as well as the number of arithmetical operations, which are required in solving them. 
Twelve math word problems were compiled: eight with consistent language, out of which four with one operation required four with two or more operations, and four other problems with inconsistent language (table 3). The same procedure was repeated twice with different problems: once in the pre-test, and later, after the intervention, once again, twelve new problems, equivalent in measure with the problems of the pre-test, were delivered in the post-test. All the learners completed their tasks on a leaflet in pencil and the researchers and the instructors led the process. Learners were assessed by points in solving math word problems in both stages of testing (pre-test and post-test) as follows: 2 points for the task solved completely correctly, 1 point if the procedure or the result was correct, and 0 points if the problem solving process failed entirely. Reliability for the pretest and the post-test (Alpha Cronbach) for the fifth grade was 0.737 and 0.786 respectively, whereas for the third grade 0.575 , respectively 0.649 .

Table 3. Examples of math word problems used in the pre-test and post-test stages

\begin{tabular}{lll}
\hline Word Problems Examples & $\begin{array}{l}\text { Can be solved } \\
\text { by one } \\
\text { arithmetic } \\
\text { operation }\end{array}$ & $\begin{array}{l}\text { Can be solved by } \\
\text { two or more } \\
\text { arithmetic } \\
\text { operations }\end{array}$ \\
\hline $\begin{array}{l}\text { Director Toni directed a film which ran for } 248 \text { minutes. During the editing } \\
\text { process, } 109 \text { minutes were removed. What is the final running time of the } \\
\text { film, after editing? }\end{array}$ & $\sqrt{ }$ \\
\hline Hana read a book with 112 pages for three days. The first day she read 29 & \\
pages, on the second day she read the twice of the first day's pages. How \\
many pages should read Hana on the third day?
\end{tabular}

\section{Procedure}

Intervention in this study was based on the program IMPROVE of the authors Mevarech \& Kramarski (1997). The program represents a multidimensional teaching method that includes three main components: a) facilitation of the two strategies, acquisition, and the processes of meta-cognitivism; b) learning in collaborative groups of learners with diverse previous knowledge, and c) provision of rich corrective information that focuses on lower and higher order cognitive processes. The intervention was also based on the cognitive model for self-correcting strategies SOLVE IT! That enhances the problem solving abilities (Montague et al., 2008). The modified program for intervention in this project was titled "Metacognitive instruction for solving math word problems" and was implemented within a period of a month. During this period, the instructors of the four experimental classes conducted regular meetings with two of the researchers in order to plan the instruction and the math word problems to be solved in their classes.

\section{Metacognitive instruction for solving math word problems}

The instructors of the experimental classes used the teaching strategies that are based on metacognitive questions, whose answers were discussed in detail with the learners. Learners worked in small groups and in pairs practicing solving math word problems. The groups were heterogeneous and consisted of learners with very good, good, and sufficient success score. During their collaborative work, they were expected to answer metacognitive questions in order to find the solution for math word problems.

After solving problems in small groups, the instructors initiated the discussion with "the whole class" following the question-answer format. All the questions in the sequence were discussed in the class, and by the end of the lesson, the instructor illustrated the solution of the math word problem analyzing learners' responses.

Metacognitive questions and the steps:

Comprehension. What is the problem about? Learners are expected to describe the problem in their own words focusing on mathematical content. Comprehension questions give learners orientation in clarifying the main ideas in the problem, and in elaborating the concepts (e.g. "Describe... in your own words", "What information is presented in the problem?" "What is required? "Is information in line with the question or the requirement?"

Check: Is the problem understood?

Connections. Learners are asked to identify keywords in the problems and to find their connections with mathematical operations based on the tasks performed earlier (e.g. "In what ways is this problem that you have to solve similar or different from the problems we have solved earlier?" "What do the words...mean and how do they connect with arithmetical operations?"

In order to find connections between the parts of the problem learners "underline" words or expressions, and complete the wall of words placed in the classroom and in their notebooks. (The wall of words is a sheet of paper divided into four columns. On each of the columns, learners classify expressions such as plus, minus, more than, sum, less than, subtract, decreases, product, double, multiply, is divided, is halved, etc. based on operations: addition, subtractions, multiplication, and division).

Check: Is the necessary information underlined? What is the connection with mathematical operations? What is being sought?

Strategies. Which are the most suitable strategies for solving the problems, and why? (Numerical data and the "operations" in math word problems are organized based on a scheme, or drawing, and a decision is made regarding the steps and operations that are required. The symbols for operations are written $(+,-, x$, and $\div)$ that are necessary in order to find the solution. 
Check: Is the scheme (drawing) suitable for the given problem? Are the connections between parts of the problem presented?

Calculations. Write mathematical expressions and make the appropriate calculations.

Check: Have the calculations were made in the appropriate sequencing? Does the solution make sense?

Reflections. Does the solution make sense? Have I got it right? Can I solve the problem in a different way? Which is your explanation? Learners need to reflect on their own as problem solvers regarding the problem solving process, as well as the solution itself.

After having solved "the equation" learners are instructed to have a look at the visual representation and to decide whether their solution makes sense. Learners are encouraged to reread the math world problem and to have a look at the diagram that represents the sentence (in the drawing) in order to make sure that the information is correctly presented. Noting down the relations between the numerical data (quantity) in the problem with symbols and drawings aids learners in all the steps described above.
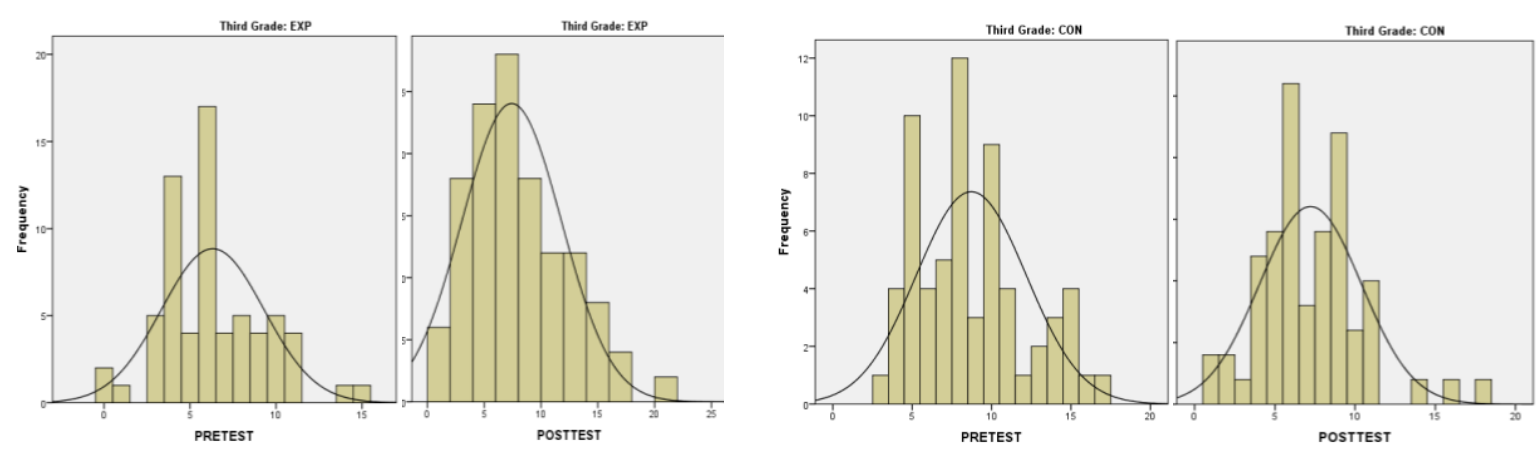

Figure 1. Distribution of variables in the pre-test and the post-test of the third grade in experimental and control group
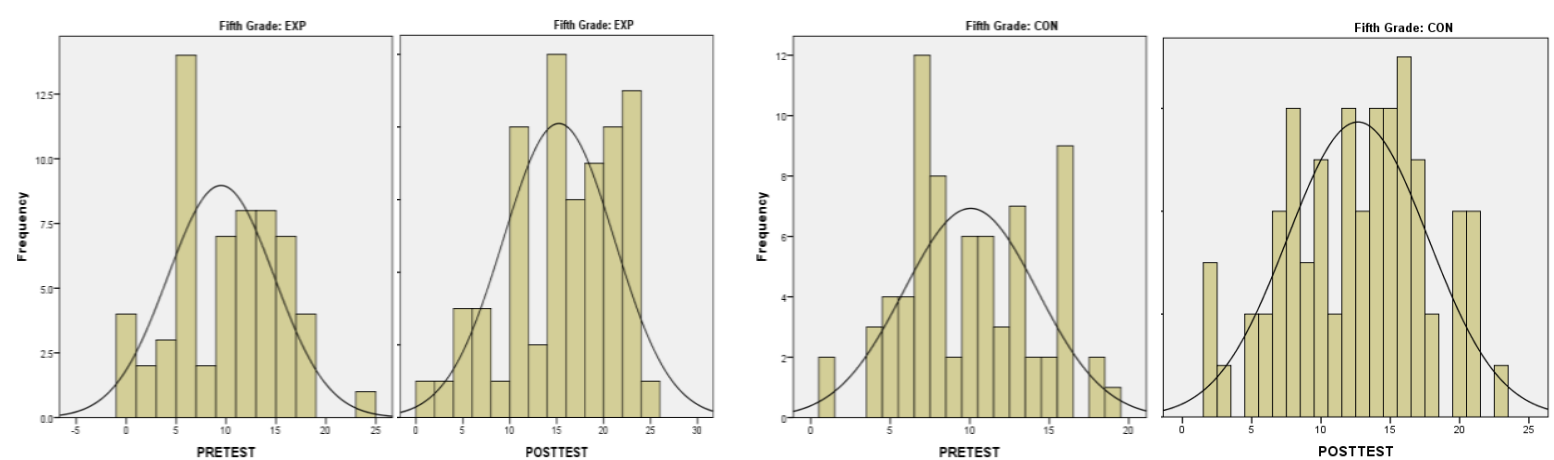

Figure 1. Distribution of variables in pre-test and post-test of the fifth grade in experimental and control group

In the Table 4 are presented the basic statistics for the pretest and the post-test: math word problems with one operation (1-4), with two or more operations (9-12), and those with inconsistent language (5-8).

In order to verify the research hypothesis, particular analyses were conducted for the third and for the fifth grade. In both groups of learners (third and fifth grade), Ttest was utilized in order to compare the results of the pre-test and the post-test.

The comparison of the results of the control group and the experimental group in the pre-test with third graders has shown that they are statistically different (the
Check: Is my answer correct? Is everything all right? If not, go back and seek help if you need it.

[Metacognitive questions for solving word problems modified from Maverech \& Kramarski (1997) and Montague, Wagner \& Morgan (2000).]

\section{Results}

In order to examine the impact of instruction based on metacognitive and self-regulating strategies in solving math word problems by the learners of the third and the fifth grade, the points scored in the pre-test and the posttest were analyzed in different ways.

On figure 1 and figure 2, the distribution of variables is presented. As can be observed, the distribution of variables in the pre-test and the post-test does not differ from the normal distribution in both groups of learners of the third and the fifth grade in experimental and control groups. difference is statistically valid, $p=0.000$ ), whereas the results of the post-test indicate that the difference between the two groups is not significant $\left(t_{(128)}=2.83\right.$, $p=0.778$. Hence, it can be concluded that there is no significant difference between the control group and the experimental group of the third graders as the result of the intervention.

The pre-test results do not display any difference between the groups of the fifth grade $(p=0.514)$, whereas there are differences in average results of the post-test between the experimental and the control group $\left(t_{(131)}=2.702\right.$ and $\left.p=0.008\right)$. 
In order to assess the effect of intervention with the learners of the fifth-grade analysis of covariance (ANCOVA) was utilized. This analysis was used solely for the results of the fifth graders since the third grader's groups were not equal at the beginning that is the homogeneity of variances was not ensured. The overall result of the post-test, the results of the problems with one operation (1-4), with two and more operations (9-12) and of those with inconsistent language (5-8) were analyzed separately by the use of ANCOVA, and the respective pre-test results as a covariance in each of the analyses. Hence, the total of points from each group of problems was considered as dependent variables. The results show that the difference between the averages of points in the pre-test and the post-test is significant
$F_{(1,130)}=20.54$ and the value $p<0.0001$. Based on the data on table 4, differences between the experimental and control group the before the commencement of the research. Thus, the learners from the experimental group considerably outdid the control group in the total of points scored in the post-test. Finally, calculation of the extent of effectiveness (ES) showed that the learners of the experimental group benefited from metacognitive instruction ( $E S=0.136)$, even though this is a small benefit.

Table 5 summarizes the findings of ANCOVA regarding the overall number of points in the posttest for each group of math word problems.

Table 4. Presentation of the points in general, average points, standard deviation in math word problems with consistent language and word problems with inconsistent language based on the treatment (exp/cont), class level (3/5), and the time of intervention (before/after)

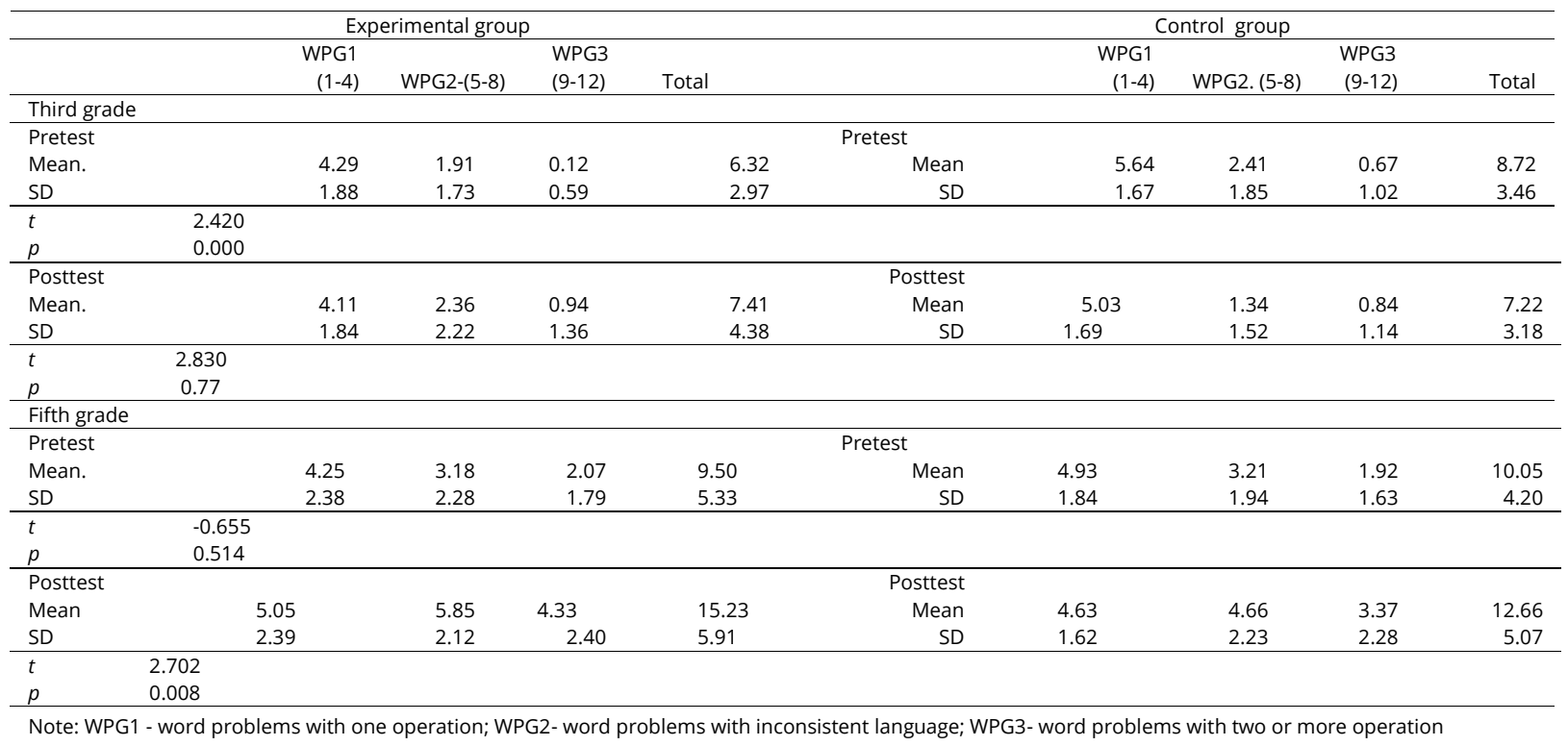

Table 5. Summary of the findings derived from ANCOVA

\begin{tabular}{|c|c|c|c|c|c|}
\hline \multirow[t]{2}{*}{ Source } & \multirow[t]{2}{*}{ Df } & \multicolumn{4}{|l|}{$F$} \\
\hline & & Total score & WPG1 & WPG2 & WPG3 \\
\hline Treatment & 1 & $20.548^{\star \star \star *}$ & $4.539 *$ & $12.23 * *$ & $6.28^{*}$ \\
\hline
\end{tabular}

Table 6. Presentation of overall points, average points, standard deviation in the pre-test and post-test according to overall success score of the third and fifth-grade learners

\begin{tabular}{|c|c|c|c|c|c|c|c|c|c|}
\hline \multicolumn{5}{|c|}{ Experimental Group } & \multicolumn{5}{|c|}{ Control Group } \\
\hline & Sufficient & Good & Very good & Total & & Sufficient & Good & Very good & Total \\
\hline \multicolumn{10}{|c|}{ Third grade } \\
\hline Pretest & & & & & Pretest & & & & \\
\hline Mes. & 5.13 & 5.58 & 6.92 & 6.32 & Mean & 4.25 & 6.46 & 9.72 & 8.72 \\
\hline SD & 5.36 & 2.43 & 3.01 & 2.97 & SD & 0.95 & 1.85 & 3.36 & 3.46 \\
\hline Posttest & & & & & Posttest & & & & \\
\hline Mean & 5.38 & 5.53 & 8.74 & 7.41 & Mean & 4.50 & 4.54 & 8.19 & 7.22 \\
\hline SD & 3.11 & 2.85 & 4.76 & 4.38 & SD & 1.22 & 2.43 & 2.93 & 3.18 \\
\hline
\end{tabular}




\begin{tabular}{|c|c|c|c|c|c|c|c|c|c|}
\hline \multicolumn{10}{|c|}{ Fifth grade } \\
\hline Pretest & & & & & Pretest & & & & \\
\hline Mean & 0.80 & 8.15 & 11.51 & 9.5 & Mean. & 4.28 & 8.24 & 11.86 & 10.05 \\
\hline SD & 1.30 & 4.27 & 4.76 & 5.33 & SD & 7.63 & 2.99 & 3.77 & 4.2 \\
\hline \multicolumn{5}{|c|}{ Posttest } & \multicolumn{5}{|c|}{ Posttest } \\
\hline Mean & 4.80 & 12.00 & 18.57 & 15.23 & Mean & 7.63 & 10.57 & 14.57 & 12.66 \\
\hline SD & 2.58 & 4.55 & 3.82 & 5.91 & SD & 4.30 & 3.94 & 4.72 & 5.07 \\
\hline
\end{tabular}

From the data given in table 5 , it is observed that learners are more likely to benefit from metacognitive instruction and self-regulating strategies in solving more complex word problems than in simple problems. The reason for this lies in the fact that in simple problems learners already have sufficient cognitive/mental tools at their disposal, whereas for more complex problems, comparisons, reasoning, exchange of information, among others, self-regulating strategies seem to be more effective since they learn how to act in order to make a decision.

Table 6 presents the averages and the standard deviation for the pre-test and post-test results analyzed according to learners' overall success score (sufficient, good, and very good). The results indicate an increase in success in the experimental groups of both classes because of the intervention. However, while in the third-grade classes only learners with very good success score benefit from intervention, the effect of the intervention is observed in all learners of the fifth grade; not only in learners with very good success score but also in those with good and sufficient success score. As far as gender is concerned, after the intervention in the experimental groups of the fifth-grade classes, no significant difference between girls and boys is observed $\left(F_{(1.131)}=0.106\right.$ and $\left.p=0.745>0.05\right)$. Similarly, there is no significant difference regarding the results of groups of third-grade classes $\left(F_{(1.127)}=3.715\right.$ and $p=0.056>0.05$ ).

\section{Discussion and Conclusion}

The study aimed at investigating the effect of instruction based on metacognitive strategies in successful solving of math word problems, examining whether its effect is greater in the third or the fifth grade. Furthermore, the research addressed the issues whether this type of intervention based on metacognitive strategies has a greater effect on male or female learner, learners with very good, good, or sufficient success score. It also examined in which problems the extent of its effectiveness is greater: in solving math word problems with consistent language, with one operation, with two or more operations, or with inconsistent language.

The data that derive from this study show that there are differences in solving math word problems between the learners of the third and fifth graders. The latter graders displayed a better performance, as it was expected. The reason for this, as was indicated by the study, is that the learners' metacognitive abilities, in linguistic analysis of texts, and in consequence, their resulted in more precise understanding and application of particular arithmetical operations. As it is observed from the research data, both groups of learners, the third and the fifth grades, who received appropriate instructions based on metacognitive and self-regulating strategies on the manner of treatment of math word problems, achieved better results compared to their peers who were not given any instruction of the kind. This conclusion is supported by earlier studies as well, which shows that effective use of instruction based on metacognitive and self-regulating strategies enhances learners' ability in solving math word problems (Mevarech et al., 2010; Fuchs et al, 2006; Montague et al., 2000).

The findings that derive from this study confirm that the learners of both group, of the two grades, grade three and five, proved to be more successful after the intervention in solving problems with inconsistent language, that is the problems in which linguistic information was not consistent with the arithmetical operations. This is fully in line with the research of Mevarech et.al. (2010), in which the importance of metacognitive instruction in solving this type of problems is emphasized. In this study, the findings show that, as a result of intervention and of learners' collaborative work, learners focus to a greater extent on problems with inconsistent language and more complex problems, for solving of which application of two or more arithmetical operations are required. This could also be the reason why learners' performance in one's step problems that require the application of only one arithmetical operation and are easier to be solved, yields an almost same result, both in the pre-test and the post-test.

It have been proven in many studies that effective teaching strategies require the inclusion of metacognitive and self-regulating processes (Blair, et al, 2015; Montague, Enders \& Dietz, 2011; Özsoy \& Ataman, 2009; Mevarech, 1999; Quintero, 1983). Based on the present study results, it can also be claimed that cognitive and self-regulating strategies used by learners in order to control their actions, to reason, and to reflect, are the main resources of attention that they need when they are solving a problem. This enables them to plan and to organize linguistic information, to comprehend the relations between the concepts, and then select arithmetical operations correctly. Hence, based on the conclusions of the study of Blair at al. (2015), in general, learners need to be provided specific support for focusing on self-regulating abilities in their early childhood in order to enable greater development of their academic abilities.

Many studies argue that the development of mathematical vocabulary constitutes the key factor that helps learners in enhancing their skills in solving math word problems (Monroe \& Orme, 2010; Capraro \& 
Joffrion, 2006; Lee \& Leah, 2007; Montague, at. al., 2008). The present study also indicates that the learners of both groups, especially those of the third grade, in the majority of problems encounter difficulties in understanding the key words and "translating" them into mathematical language, or "interpreting" them as arithmetical operations. In the studies of Daroczy et al. (2015) and Hegarty et al (1995), that the factors of these difficulties are related to the semantic presentation of the problem, which has the greater indirect influence on reading comprehension than on comprehending of the mathematical problems are also discussed. Hence, the present research indicates that as a consequence of inaccurate analysis of the text of the problem, the solution of math word problem results erroneously.

While in the study of Mevarech et al (2010) on metacognitive instruction learners of different ages benefited, the effect of intervention being seen with youngest learners in the age largely, in the present study greater effect is observed with the learners of the fifth grade. This finding can be explained based on a number of factors investigated by the research. Initially, thirdgrade learners lack experience in focusing on cognitive and self-regulation processes. Engagement of learners in solving math word problems for a short period is insufficient for improvement of their results. Since they are exposed solely on solving tasks that more than often require memorization of the procedures, learners lack the habit of using appropriate strategies for solving math word problems.

Another reason that relates to dissatisfactory results are the teaching materials used during the intervention in experimental classes, which, according to the evaluation of the teachers in experimental classes, particularly the teachers of the third grade, are materials that contain a high percentage of challenging problems. In their regular program, learners use textbooks of mathematics that contain an insufficient number of math word problems.

The findings of this study raise a number of issues for further research: What are the effects of a program based on metacognitive and self-regulating strategies if it is applied for a longer period? How can the program be modified so that it has an effect on training pre-service and in-service teachers? Is there a need for adopting these methods at all levels, in primary school, as well as in higher grades of lower secondary schools?

Finally, it is suggested that the studies related to solving math word problems should take into consideration other approaches as well. Different learners have different needs. Consequently, it is a necessity that initially the difficulties that learners face during the process of solving these problems are understood. Individual differences that relate to language, numerical abilities, and general cognitive abilities should be considered crucial in orienting learners for applying cognitive components of reading and mathematics if we want our learners to become successful math word problem solvers. Mandatory inclusion of math word problems in the curriculum, as well as an application of self-regulating and metacognitive strategies, would facilitate learners' manner of reasoning and would increase learners' skills for generalizing knowledge and for solving the problems from daily life.

\section{Acknowledgements}

This research was funded by a grant of MEST (Ministry of Education Science and Technology) of Kosovo.

\section{References}

Avdyli, Rr. \& Cuetos, F. (2012). Reading difficulties in Albanian. Annals of Dyslexia. 62(3), 137-152.

Bestgen, Y. (2009). Computational requirement and the misunderstanding of language inconsistent word problems. In Taatgen,N., \& van Rijn, H (Eds.). Proceedings of the 31st Annual Meeting of the Cognitive Science Society (pp.1500-1505). Amsterdam, Netherlands: Curran Associates, Inc.

Blair, C., Ursache, A., Vernon-Feagans, L., \& Greenberg, M. (2015). Multiple Aspects of Self-Regulation Uniquely Predict Mathematics but Not Letter-Word Knowledge in the Early Elementary Grades. Development Psychology. 51(4), 459-472.

Boonen, J.H.A., van Wesel, F., Jolles, J., \& van der Schoot, M. (2014). The role of visual representation type, spatial ability, and reading comprehension in word problem solving: An item-level analysis in elementary school children. International Journal of Educational Research. 68,15-26. https://doi.org/10.1016/j.jjer.2014.08.001.

Capraro, M. M., \& Joffrion, H. (2006). Algebraic equations: Can middle school students meaningfully translate from words to mathematical symbols? Reading Psychology 27, 147-164.

Capraro, M. R., Capraro, M.M., \& Rupley, H.W. (2012). Reading-enhanced word problem solving: a theoretical model. European Journal of Psychology of Education 27, 91-114.

Castro-Martinez, E., \& Frias-Zorilla, A. (2013). Two step arithmetic word problems. The Mathematics Enthusiast. 10 (17). 379-406.

Daroczy, G., Wolska, M., Meurers, D. W., \& Nuerk, H. (2015). Word problems: a review of linguistic and numerical factors contributing to their difficulty. Frontiers in Psychology. 6:348. https://doi.org/10.3389/fpsyg.2015.00348

De Corte, E., Verschaffel, L., \& Op't Eynde, P. (2000). Selfregulation: A characteristic and a goal of mathematics education. In M. Boekaerts, P. R. Pintrich, \& M. Zeidner (Eds.), Handbook of self-regulation (pp. 687-726). San Diego: Academic Press.

Fuchs, L.S., Fuchs, D., Compton, L. D., Powell, R. S., Seethaler, M.P., Capizzi, M.A., Schatschneider, C., \& Fletcher, M.J. (2006). The Cognitive Correlates of ThirdGrade Skill in Arithmetic, Algorithmic Computation, and Arithmetic Word Problems. Journal of Educational Psychology. 98(1), 29-43. 
Fuchs, L.S., Seethaler, M.P.,Powell, R. S., Fuchs, D., Hamlett, L. C., Jack, M. F. (2008). Effects of Preventative Tutoring on the Mathematical Problem Solving of Third-Grade Students with Math and Reading Difficulties. Exceptional Children, 74(2), 155-173.

Griffin, C. C \& Jitendra, K. A. (2009). Word Problem solving Instruction in Inclusive Third-Grade Mathematics Classrooms. The Journal of Educational Research, 102(3), 187-201. http://dx.doi.org/10.3200/JOER.102.3.187-202

Hegarty, M., Mayer, R. E., \& Monk, C. A. (1995). Comprehension of arithmetic word problems: A comparison of successful and unsuccessful problem solvers. Journal of Educational Psychology, 87, 18-32.

Hickendorff, M. (2013). The Language Factor in Elementary Mathematics Assessments: Computational Skills and Applied Problem. Solving in a Multidimensional IRT Framework. Applied Measurement in Education, 26, 253-278.

Hiebert, J. (Ed.) (1986). Conceptual and procedural knowledge: The case of mathematics. Lawrence Erlbaum Associates, Publishers, Inc. Hillsdale, NJ.

Haylock, D., \& Thangata, F. (2007). Key concepts in teaching primary mathematics. London: Sage Publication.

Jitendra, A., Griffin, C., Haria, P., Leh, J., Adams, A., \& Kaduvettoor, A. (2007). A comparison of single and multiple strategy instructions on third-grade students' mathematical problem solving. Journal of Educational Psychology, 99, 115-127.

Jonassen, H. D. (2003). Designing Research-Based Instruction for Story Problems. Educational Psychology Review, 15(3), 267-296.

The Pre-University Education Curricula Framework of Republic of Kosovo (2016). Retrieved from http://masht.rks-gov.net.

Lubin, A., Houde, O., \& de Neys, W. (2015). Evidence for children's error sensitivity during arithmetic word problem solving. Learning and instruction, 40, 1-8.

Lee, H. J., \& Leah, M. H. (2007). Teaching Mathematics Vocabulary to Diverse Groups. Intervention in School and Clinic, 43(2), 121-126.

Lewis, A. B. (1989). Training students to represent arithmetic word problems. Journal of Educational Psychology, 81, 521-531.

Leong, K. Che., \& Jerred, W. D. (2001). Effects of consistency and adequacy of language information on understanding elementary mathematics word problems. Annals of Dyslexia, 51, 277 - 298.

Martinez, J., \& Martinez, N. (2001). Reading and writing to learn mathematics: A guide and resource book. Boston, MA: Allyn Bacon.

Mevarech. Z. R., \& Kramarski, B. (1997). IMPROVE. A Multidimensional Method for Teaching Mathematics in Heterogeneous Classrooms. American Educational Research Journal. 34(2), 365-394.
Mevarech, Z. R. (1999). Effects of metacognitive training embedded in cooperative settings on mathematical problem solving. The Journal of Educational Research, 92, 195-205.

Mevarech, Z. R., Terkieltauh, Sh., Vinberger, T. \& Nevet, V. (2010). The effects of metacognitive instruction on third and sixth graders solving word problems. ZDM Mathematics Education, 42,195 -203.

Monroe, E. E., \& Orme, M. (2010). Developing mathematical vocabulary. Preventing School Failure: Alternative Education for Children and Youth, 46(3), 139142. http://dx.doi.org/10.1080/10459880209603359

Montague, M., Wagner. C., \& Morgan, H. Th. (2000). Solve it! Strategy Instruction to Improve Mathematical Problem Solving. Learning Disabilities Research and Practice, 15(2), 110-116.

Montague, M., Krawec, J. \& Sweeney, C. (2008). Promoting Self-Talk to improve Middle School Students' Mathematical Problem Solving. Perspectives on Language and Literacy, 34(2) 13-17.

Montague, M., Enders, C., \& Dietz, S. (2011). Effects of Cognitive Strategy Instruction on Math Problem Solving of Middle School Students with Learning Disabilities. Learning Disability Quarterly 34(4) 262272.

OECD (2003).The PISA 2003 Assessment framework: mathematics, reading, science and problem solving knowledge and skills. Paris: OECD. Retrieved from, http://files.eric.ed.gov/fulltext/ED480801.pdf

OECD (2014), PISA 2012 results: Creative Problem Solving: Students' Skills in Tackling Real-Life Problems (Vol. V). Paris: OECD.

Österholm, M. (2005). Characterizing reading comprehension of mathematical texts. Educational Studies in Mathematics, 63, 325-346.

Özsoy, G. \& Ataman, A. (2009). The effect of metacognitive strategy training on mathematical problem solving achievement. International Electronic Journal of Elementary Education, 1(2), 68-83.

Özsoy, G. \& Kuruyer H. G. \& Çakiroğlu, A. (2015). Evaluation of Students' Mathematical Problem Solving Skills in Relation to Their Reading Levels. International Electronic Journal of Elementary Education, 8(1), 113132.

Pape, J.S. \& Smith. C. (2002). Self-Regulating Mathematics Skills. Theory into practice. 41(2), 93-101.

Pimm, D. (1991). Discourse analysis and mathematics education: An anniversary of sorts. In N. Ellerton, \& K. Clements (Eds.), Mathematics and language: A review of language factors in mathematics learning. Geelong, Australia: Deakin University Press.

Quintero, A. H. (1983). Conceptual understanding in solving two-step word problems with a ratio. Journal for Research in Mathematics Education. 14(2), 102-112. 
Reys, R. E., Lindquist, M. M., Lambdin, D. V., Smith, N. L., \& Suydam, M. N. (2001). Helping children learn mathematics (6th ed.). New York: John Wiley \& Sons, Inc.

Schraw, G., Crippen, K. J., \& Hartley, K. (2006). Promoting self-regulation in science education: Metacognition as part of a broader perspective on learning. Research in Science Education, 36, 111-139.

Stern, E. (1993). What makes certain arithmetic word problems involving the comparison of sets so difficult for children? Journal of Educational Psychology, 85, 723.

Stoeger, H., Fleishmann, S. \& Obergriesser, S. (2015). Selfregulated learning (SRL) and the gifted learner in primary school: the theoretical basis and empirical findings on a research program dedicated to ensuring that all students learn to regulate their own learning. Asia Pacific Educ. Rev. 16: 257-267, DOI 10.1007/s12564-015-9376-7.

Van de Walle, J. (2004). Elementary and middle school mathematics: Teaching developmentally. ed.).Boston, MA: Allyn and Bacon/Longman, Inc.

Verschaffel, L., Greer, B., \& De Corte, E. (2000). Making sense of word problems. The Netherlands: Swets and Zeitlinger Publishers.

Vula, E., \& Bërdynaj, L. (2011). Collaborative Action Research: Teaching of Multiplication and Division in the Second Grade of Primary School. Turkish Online Journal of Qualitative Inquiry, 2(2), 7-16.

Willson, V. L., \& Rupley, W. H. (1997). A structural equation model for reading comprehension based on background, phonemic, and strategy knowledge. Journal for the Scientific Study of Reading, 1, 45-64. 
This page is intentionally left blank

www.iejee.com 